\title{
PROSPECTS FOR ALPHA PARTICLE STUDIES ON TFTR
}

\section{S.J. ZWEBEN}

PPPL -2443

DE87 013202

\author{
Princeton University \\ Plasma Physics Laboratory \\ Princeton, New Jersey 08544 USA
}

\begin{abstract}
TFTR is expected to produce approximately $5 \mathrm{MW}$ of alpha heating during the $\mathrm{D} / \mathrm{T} \mathrm{Q} \approx 1$ phase of operation in 1990. At that point the collective confinement properties and the heating effects of aipha particles become accessible for study for the first time. This paper outlines the potential performance of TFTR with respect to alpha particle production, the diagnostics which will be available for alpha paricie measurements, and the physics issues which can be studied both before and during $\mathrm{D} / \mathrm{T}$ operation.
\end{abstract}

Presented at "Symposium on Role of Alpha Particles in Magnetically Confined

Fusion Plasmas, " Goteborg, Sweden, June 1986

\section{DISCLAIMER}

This repart was prepared as an account or work sponsored by an agency of the Uniled States Goverament. Neither the United Stutes Government nor any agency theted, nor any of their employess, makcs any warranty, express or implied, or assumes any lega! liability or responsibility for the aceuracy, compleieness, or usefulness of any information, apparatus, product, or process disclosed, or represconts that its use would not infringe privately owned rights. Refe:en ie herein to any specific commercial product, process, or service by trade name, trademark, manufacturer, or otherwise does nol nccessacily constitute or imply its endorsement, recommendation, or favoring by the Unitcd States Government or any agency thereof. The views and opinions of authors expressed herein da not necessarily state or reflect those of the United States Government or any agency thereor.

\section{MASTER}

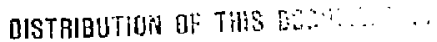




\section{Introduction}

This paper aims to give a general overview of the physics and diagnostics of alpha particles in TFTR. The study of alpha particles will naturally be divided into two phases: the pretritium phase during which "single-particle" effects can be observed with the $3.7 \mathrm{MeV}$ alphas created in the $\mathrm{D} /{ }^{3}$ He reaction or with other charged fusion products, and the D/T phase during which the population of alphas will be $\approx 1000$ times higher and "collective" effects may begin to appear. At the TFTR goal of $Q \approx 1$ alpha heating will contribute $\approx 20 \%$ to the global plasma power balance, at which point some hints about ignited plasma behavior might oe obtained.

In Sec. 2 the performance of TFTR with respect to alpha paricle creation and confinement will be described, both at the machine's present "single-paricle" level and at its projected $Q \approx 1$ level to be obtained with the addition of tritium in 1990. In Sec. 3 the potential diagnostics for TFTR alpha particle studies are outlined, and in Sec. 4 the alpha physics issues accessible for study in TFTR are briefly reviewed.

\section{Alpha Particle Creation and Confinement Properties of TFTR}

The basic creation and classical confinement properties of alpha particles in tokanaks are simple and well known. This section reviews these properties in the context of TFTR.

\section{1 "Single-Particle" Creation at $Q<<1$}

Alpha particles and other alphalike fusion products can be created at relatively low levels without the explicit addition of tritium to the discharge. In particular, the $3.7 \mathrm{MeV}$ alpha created in D ${ }^{3} \mathrm{He}$ reactions is nearly identical to the $3.5 \mathrm{MeV}$ alpha particle created in D/T reactions, although its maximum creation rate is only about $10^{-3}$ that of $\mathrm{D} / \mathrm{T}$ alphas (assuming predominanty beam-target reactions at $100 \mathrm{keV}$ deuterium beam energy). The $3.7 \mathrm{MeV}$ alpha can also be created during ${ }^{3} \mathrm{He}$ minority heating [1].

As shown in Table I, there are several other charged fusion products which can also be used to simulate single-particle alpha effects. The $1.0 \mathrm{MeV}$ triton and $3.0 \mathrm{MeV}$ proton created during normal D/D operation have nearly the same gyroradius as the $3.5 \mathrm{MeV}$ D/T alpha, and have a diagnostic advantage over the $3.7 \mathrm{MeV} \mathrm{D} /{ }^{3} \mathrm{He}$ alpha in that their creation rate can be monitored by the associated $2.5 \mathrm{MeV}$ neutron (whereas the $15 \mathrm{MeV}$ proton and $17 \mathrm{MeV}$ gamma associated with the $\mathrm{D} /{ }^{3}$ He reaction are more difficult to detect). Note that actual $D / T$ alphas are also created in TFTR without the explicit addition of tritium through the "burnup" of $1 \mathrm{MeV}$ tritons as they slow down in a background of deuterium; however, the number of these alphas is only about $1 \%$ of the number of tritons created, so that they are relatively difficult to detect. 
Thus there are several fusion products accessible for study in TFTR which can simulate D/T alpha paricles even at $\mathrm{Q} \ll<$. In the next section the expected single-particle confinement properties of these particles are described.

\subsection{Single-Particle Alpha Confinement at $\mathrm{Q}<<1$}

At the production levels described above for pretritium TFTR operation, the alphas and other charged fusion products will almost certainly not affect the plasma, so that they may be considered to be test particle "probes" of the discharge's alpha confinement properties. The expected single-particle confinement of alphas in TFTR has been calculated theoretically [2-5], and these theoretical models have alteady been incorporated into computer codes which can calculate alpha confinement for specific TFTR configurations.

The basic criterion for single-particle confinement is that the excursion of the alpha particle drift orbit from the magnetic fiux surface " $S$ " should be less than the distance between that flux surface and the vessel wall or limiter. This excursion varies inversely with the plasma curtrent, and also depends on the particle's pitch angle (with respect to the toroidal field) and to a lesser extent on the plasma cursent profile. For a typical alpha particle, roughly

$$
\delta / \mathrm{a} \approx \rho_{\mathrm{pol}} / \mathrm{R}
$$

where a and $\mathrm{R}$ are the plasma minor and major radii and $\rho_{\mathrm{pol}}$ is the alpha's gyroradius evaluated in the poloidal field.

In Fig. $l$ are some examples of calculated $3.5 \mathrm{MeV}$ alpha particle orbits in TFTR. In Figs. $1(a)$ and $1(b)$ are trajectories for particles born at $r / a=0.25$ in a plasma of moderate current $I=1.5$ MA at a toroidal field of $50 \mathrm{kG}$. Case (a) shows that an alpha born at this point with a p.tch angle of $30^{\circ}$ (cc-going) is well confined on its first orbit, while case (b) shows that an alpha born at the same place but with a pitch angle of $-30^{\circ}$ escapes to the wall on its first orbit. Figure $1(\mathrm{c})$ shows that by increasing the plasma current in the latter case to $3 \mathrm{MA}$, the previously escaping orbit becomes well confined, due to its decreased excursion from the flux surface on which it was born.

In Fig. 2 are cocie calculations by Heidbrink of the expected fraction of confined alphas in TFTR vs, plasma current, based on the model of Ref. 2 . At the lowest available currents in TFTR less than half of the alphas are confined on their first orbit, while at the highest available currents of 3 MA up to $95 \%$ of the alphas are confined on their first orbit. Note that this calculated fraction depends upon the assumed radial profile of alpha creation and on the assumed plasma current profile. With a more peaked source profile the fraction of confined alphas is larger since the alphas born near the plasma center are generally better confined. For a more peaked plasma current profile the fraction of confined alphas is larger since most of the alphas are born near the center, and the local orbit excursion decreases with increased local poloidal field. 
After its first orbit the alpha slows down primarily because of electron collisions, and loses energy without appreciable pitch angle scattering over a slowing-down tirnescale of $\tau_{s, e}$, where roughly [5]:

$$
\tau_{\mathrm{s}, \mathrm{e}}(\mathrm{sec})=1.2 \times 10^{12} \mathrm{~T}_{\mathrm{e}^{3 / 2}}(\mathrm{keV}) / \mathrm{n}\left(\mathrm{cm}^{-3}\right) \text {. }
$$

During this time the alpha's excursion from the flux surface gradually decreases due to its decreasing momentum: thus alphas which were well confined on their first orbit should generally stay confined until they have thermalized.

There are also some "nonprompt" alpha losses after the first orbit, particularly for those particles born near the pitch angle for maximum loss [2]. As calculated by Hively for TFTR, these losses should be approximately $1 \%$ of the confined alpha population for typical TFTR parameters, i.e., typically $10 \%$ of the escaping particle losses at $\mathrm{I} \approx 2.5 \mathrm{MA}$. Nonprompt losses can be distinguished from prompt first-orbit losses by the energy of the escaping alpha, since the energy loss during the furst orbit is negligible.

Note that these expectations for alpha particle confinement in TFTR come from the simplest "classical" single-particle confinement and thermalization models. More subtle physical effects associated with nonexisymmetric magnetic fieids and plasma instabilities are discussed in Sec. 4. However, this classical model comprises the basic alpha physics usually incorporated into tokamak modeling codes.

\subsection{Alpha Particles at $Q \approx 1$ in TFTR}

There are various computer simulations of the $D / T Q \approx 1$ phase of TFTR, all of which are necessarily speculative since the confinement properties of full beam power TFTR discharges are not yet known. However, in order to study the relevant physics and to prepare the appropriate diagnostics, it is useful to know the range of alpha particle effects expected for typical $Q \approx 1$ scenarios.

In Table Il are three typical TFTR $Q \approx 1$ simulations as calculated with the BALDUR code by Mikkelsen [6]. These cases differ mainly by their assumed plasma density, which is an experimental parameter that can be controlled relatively easily. The first case at the lowest density corresponds to the "energetic-ion" or "high- $T_{j}$ " mode routinely obtained in TFTR at low density and high beam power. The second case simulates a moderately higi density, normally gas-pufffueled, beam-heated discharge. The third case at the highest density adds pellet fueling and $7 \mathrm{MW}$ of ICRF heating to simulate recent upgrades to the anticipated TFTR performance. Note that these three cases do not use the same confinement model, so cannot be directly compared to one another; however, they do all have $\mathrm{Q} \approx 1$ and alpha heating power in the $4-5 \mathrm{MW}$ range. 
Radial profiles of various alpha-rejated quantities for these three sinulations are shown in Fig. 3. In Fig. 3(a) are the calculated fast alpha density profiles (for $E_{\alpha}>3 / 2 T_{1}$ ), along with the fraction of alphas which are lost on their first orbit (assuming wall radius $\approx$ plasma radius), showing that almost all alphas are confined, at least according to the classical alpha confinement model used in this code. This figure and also Fig. 3(b) show that the fast alpha density is highest in the lowest density case; this is simply due to the longer slowing down time at the lower densities (and higher electron temperatures), as shown in Fig. 3(c). The fast alpha beta is also largest in the lowest density case for the same reason, since the average fast alpha energy is a constant $(\approx 1$ $\mathrm{MeV}$ ) in the classical slowing down model. The themalized alpha density is highest at the highest density, however, since the alphas accumulate over more slowing down times in this case (and are modeled to remain on the flux surfaces of their birth in this code).

Thus for typical $Q \approx 1$ scenarios in TFTR the expected central fast alpha densities and betas are in the range $2.7 \times 10^{11}$ alphas $/ \mathrm{cm}^{3}$ and $0.3-0.8 \%$, respectively. Note that these are upper limits in the sense that nonclassical losses might also occur, as discussed in Sec. 4.

In Fig. 3(f) is shown the ratio of alpha heating to total plasma loss (excluding the losses due to sawteeth) vs radius. In none of these simulations is this ratio significantly above the global value of $P_{\alpha} / P_{\text {loss }} \approx 0.2$ expected for $Q \approx 1$ (note that the highest density case has an assumed central ICRF heating power deposition which reduces the relative importance of alpha heating in this region). Thus alpha heating would be expected to play a relatively minor (but potentially measurable) role in the power balance of these discharges.

\subsection{Alpha Particle Simulation with Neutral Beams and/or ${ }^{{ }^{3}}$ He Tails}

Some aspects of alpha particle physics might be simulated in TFTR using the large fast ion populations obtained with injected $100 \mathrm{keV}$ deuterium beams or with resonantly heated ${ }^{3} \mathrm{He}$ minority tajls [7]. In both cases the single particle confinement properties of these ions are probably similar to those of alphas of the same momentum.

Although the distribution functions of these ions are not identical to the expected isotropic alpha slowing down distribution function, an understanding of the collective instability properties of these fast ion populations might eventually be useful in developing theory appropriate to alphas in ignited plasmas. Note that in both cases the fast ion populations obtained by direct heating are comparable to or larger than the fast alpha populations obtainable at $\mathrm{Q} \approx 1$.

\subsection{Central Ignition Scenarios}

Since alpha particles should be well contained and quickly thermalized in TFTR, it should be possible (at least in principle) to obtain significant alpha heating or even self-sustained ignition. The conventional limits to TFTR performance as expressed in Table II are set by the empirical anomalous confinement properties and the empirical density and beta limits observed in tokamiks 
over the past few years; in particular, the confinement anomaly of typically 10-100 with respect to the ion neoclassical limit allows the possibility for substantial improvement of TFTR performance.

The requirements for obtaining central ignition in TFTR have been discussed recently using simplified estimntes and BALDUR simulations [8], where central ignition is defined as $P_{\alpha} / P_{\text {loss }}=1$ within some region near the center of the discharge. The requirement for central ignition is given roughly by $n(0) T_{i}(0) \tau_{E}(0) \approx 3 \times 10^{18} \mathrm{~cm}^{-3} \mathrm{eV} \mathrm{sec}$ at $T_{\mathrm{i}}(0) \approx 10 \mathrm{keV}$. If these central conditions can be obtained with peaked density profiles (typically $n(0) / \bar{n} \equiv 2.7$ ), then the resulting average censities and betas are less than a factor of two above their empirical limits. Thus a possible approach to central ignition in TFTR is similar to that described by the third case in Table II, but with a central confinement time of $\approx 1 \mathrm{sec}$ instead of the assumed $0.23 \mathrm{sec}$ in that simulation. It remains to be seen whether the long cenual confinement times obtained recently in TFTR with pellet injection can be sustained at high central temperature.

\section{Alpha Particle Diagnostics}

Prospects for alpha particle diagnostics have improved gradually over the past few years [9]. This section will review the diagnostics available for TFTR without discussng the longer range diagnostic possibilities applicable to the next-generation ignited tokamaks.

\subsection{Escaping Alphas}

Escaping alphas can be detected relatively easily using techniques analogous to those developed for escaping 3 and $15 \mathrm{MeV}$ protons on PLT and PDX [10,11]. The principal difficulty derives from the need to teplace the standard silicon surface barier diode with a detector suitable for use in the harsh neutron environment at $Q \approx 1$ in TFTR.

A prototype inorganic scintillator detector compatible with this required leve! of radiation resistance has been installed recently on TFTR [12]. It consists of an $\approx 10 \mu$ microcrystalline layer of $\mathrm{ZnS}(\mathrm{Ag})$ onto which escaping alphas, tritons, and protons impact after having passed through a $3 \mu$ aluminum foil shield. These impacts produce visible scintillations which are fiber optically coupled to photomultiplier tubes for either pulse or flux counting. For $3.5 \mathrm{MeV}$ alphas and 1.0 $\mathrm{MeV}$ tritons the counting efficiency of this detector is nearly $100 \%$, while for neutrons and yammas the efficiency should be $\approx 10^{-4}$ and $10^{-6}$, respectively.

A more advanced version of this detector is shown schematically in Fig. 4. Alphas and other fusion products pass successively through a pinhole and slit iperature [1] which disperpes the particles on to the 2-D scintillator screen according to their pitch angle and gyroradius (energy). The scintillator screen is then imaged onto a coherent fiber bundle and the image is recorded with an intensified video camera. An array of detectors similar to this is planned for installation on TFTR in 1987. Simpler modular detectors will also be installed at various points on the vessel wall to 
monitor possible anomalous or ripple-induced losses.

Other possible escaping alpha detectors are described in Ref. 9.

\subsection{Charge Exchange Recombination Spectroscopy}

Slow-confined alphas with energies up to $\approx 500 \mathrm{keV}$ can be diagnosed spectroscopically through a single charge-exchange process between the alpha and the $80 \mathrm{keV}$ diagnostic neutral beam [13]. This technique has already been used to measure thermal helium atoms at a density of $\approx 10^{12} \mathrm{~cm}^{-3}$ in $P D X$, which is about the density expected for thermalized alphas at $Q \approx 1$ in TFTR (see Fig. 3).

This diagnostic can, in principle, measure the jadial profile of slow alphas, including also some pitch angle and energy resolution determined by the angle and energy of the diagnostic neutral beum. The principal difficulty is the harsh neutron background expected at $Q \approx 1$. This background can be evaluated as soon as this system is installed on TFTR, although its use for alpha diagnostics will require $Q \approx 1$ conditions.

\subsection{Double Charge Exchange}

The slow-confined alphas can also doubly charge exchange with neutral helium aro:ns introduced either with a diagnostic neutral beam [14] or by doping the plasma with helium gas. Recently, Hammett has used the latter technique to measure charge-exchanged ${ }^{3} \mathrm{He}$ tail ions up to an energy of $150 \mathrm{keV}$ in a ${ }^{4} \mathrm{He}$ background plasma in PLT $[15]$. The fast ${ }^{3} \mathrm{He}$ density was $\approx 10^{12}$ $\mathrm{cm}^{-3}$ and the background neutral helium density 'was $\approx 10^{8}-10^{10} \mathrm{~cm}^{-3}$ in this case.

This diagnostic could, in principle, measure the radial profile of slow alphas, with pitch angle and energy resolution set by both the diagnostic neutral beam and by the charge exchange analyzer itself. The principal difficulty will again be the neutron background expected at $Q \approx 1$. Various charge exchange analyzers capable of making this measurement already exist on TFTR, allhough application to alpha measurements will probably require $Q \approx 1$ conditions.

\subsection{Burnup Measurements}

The confinement properties of alphalike $1 \mathrm{MeV}$ tritons and $0.8 \mathrm{MeV}{ }^{3} \mathrm{He}$ created by D/D reactions can be determined through the bunup of these ions in the background denterium [10,11]. The fractional burnup catn be measured by the ratio of $14 \mathrm{MeV}$ D/T neutrons to $2.5 \mathrm{MeV} \mathrm{D} / \mathrm{D}$ neutrons (for the triton burnup), or by the ratio of escaping $15 \mathrm{MeV}$ protons to $2.5 \mathrm{MeV}$ neutrons (for the ${ }^{3} \mathrm{He}$ burnup). This result can be compased to the expected $\approx 1 \%$ burnup assuning classical fusion product confinement. 
Preliminary measurements of the triton bumup fraction have already been made in TFTR by Nieschmidt[16] and Cecil[17] using foil activation and an NE213 scintillator, respectively, and ${ }^{3} \mathrm{He}$ burnup measurements have already been made in TFTR by Strachan using silicon surface barrier detectors[18]. These measurements will be very useful for providing a global view of fusion product confinement, but will not have the space or time resolution which might be necessary to identify specific anomalous loss mechanisms.

\subsection{Fusion Gamma Diagnostics}

Gamma rays are emitted during $D / T$ and $D / 3$ He fusion reactions, and so can be used to monitor the alpha production rate, especially for the latter reaction which produces no neutrons. Standard sodium iodide and NE226 scintillation detectors have recentily been used to look for the $17 \mathrm{MeV}$ gamma during deuterium injection into a ${ }^{3} \mathrm{He}$ plasma [17].

Alpha panicles can potentially be diagnosed directly through the gammas emitted during their reactions with tritium or ${ }^{7} \mathrm{Li}$ [19]. The main difficuliy with this technique is the large backgrounds expected from neutron-induced gammas.

\subsection{ICRF Emission}

Superthermal alphas should emit electromagnetic radiation at high harmonics of their gyrofrequency, whereas deuterium ions (which have the same fundamental frequency) should enit predominantly at low harmonics. Detection of this radiation using a standard RF antenna at the plasma boundary has been proposed as an alpha diagnostic [20], and an experiment in JET has already correlated the population of charged fusion products with characteristic ICRF emission [21].

This technological requirements for this detection system are relatively simple compared to other potential alpha diagnostic techniques. However, the received radiation will have to be interpreted through theoretical models in order to determine the alpha particle populations. A similar detection system has been used on PDX to examine electronagnetic emission characteristic of fishbone instabilities, arả so may also be useful for monitoring alpha pirticle instabilities at $\mathrm{Q} \approx 1$.

\section{Physics Issues Concerning Alpha Particles in TFTR}

The physics issues for alpha particles in TFTR again divide naturally into those "single-particle" effects accessible for study without the use of tritium at $Q<<1$, and those effects concerning the "collective" confinement and healing properties of alphus which begin to be accessible at $Q \approx 1$. These physics issues will be reviewed briefly in relation to the available TFTR performance and diagnostics. 


\subsection{Tests of the Classical Single-Particle Confinement Model}

The simple classical alpha confinement model described in Sec. 2.1 can be used to predict the alpha confinement properties of TFTR; for example, Fig. 5 shows the escaping alpha flux vs. pith angle for two different plasma currents at a position $\approx 20 \mathrm{~cm}$ outside the plasma at the bottom of the vessel. Since the escaping alpha detectors described in Sec 3.1 should be capable of making absolute flux vs pitch angle measurements they should be able to check such predictions, at least to within the uncertainty associated with the plasma current and alpha source radial profiles (as estimated from the electron temperature and neutron emission profiles).

Anomalous confinement of alphas could be inferred from the escaping alpha detectors in various ways: for example, the escaping fiux might have fast fluctuations (e.g. ,correlated with MHD activity), the picch angle distribution might show unexpected flux at large angles (indicating alphas transported to the plasma edge), and/or the expected noriprompt loss at low energies may not appear (indicating spatial loss rates competitive with energy loss rates).

Information about the slow-confined alphas would also be useful in testing single-particle confinement, since the classical model predicts that nearly all alphas which are confined on their first orbit will remain confined until thermalized. For example, if the local central density of alphas is less than expected, it suggests that these particles anomalously diffuse radially during a slowing down time. Note, however, that the low energy alpha popuiation depends on both the local source rate and also the local slowing down time, so that an unexpected depletion of these particles might also be interpreted as an anomalously fast thermalization. Unfonunately, the charge exchange diagnostics described in Secs. 3.2 and 3.3 will probably not be useful at $Q \ll<1$.

More accessible tests of the global confinement of alphas can be made indirectly through the burnup measurements of tritons and ${ }^{3} \mathrm{He}$ as described in Sec. 3.5. For example, the current dependence of the predicted confined alpha fraction as shown in Fig. 2 should be reflected in the burnup fraction, as already shown on PLT and PDX [10] at relatively low currents. Again this measurement is somewhat ambiguous in that anomalously low burnup can be interpreted either as anomalous loss or anomalously fast thermalization.

Taken together these three techniques should be able to characterize the single-particle alpha confinement at least as well as the neutral beam ton or ICRF tail ion confinement has been characterized to date. The following sections outline some specific physical effects relevent to possible aromalous alpha behavior in TFTR. 


\subsection{Ripple Effects}

Alphas can be deconfined by toroidal field ripple through three distinct mechanisms: ripple trapping in local magnetic wells [22,23], diffusion of nonripple-trapped banana orbits by random walks due to ripple at the banana tips [24], and resonance between the alpha gyro orbit and the ripple period [25]. Although these mechanisms were not discussed above, they are also "classical" in the sense that they can be precisely calculated given the magnetic structure of TFTR.

Ripple-trapping regions in TFTR exist along thw outer half of the plasma typically outside r/a $\approx 0.6$ at $45^{\circ}$ from the outer equatorial plane and outside $\mathrm{r} / \mathrm{a} \approx 1$ at the vessel bottom. All alphas born within these regions with sufficiently large pitch angles will be lost to the wall promptly; hovrever, for normal alpha source profiles this should result in a negligible alpha loss fraction. This ripple loss can be checked using escaping alpha detectors arrayed torvidully across one tipple period.

Ripple-induced diffusion of banana-trapped alphas could also lead to losses which are spatially modulated with the toroidal ripple period. As calculated recently by white [26], this mechanism ought to deconfine rapidly all alphas in TFTR with banana tips outside a radius typically $\mathrm{r} / \mathrm{a} \approx 0.6$. These losses might be distinguished from axisymmetric prompt losses as a function of plasma current, since these ripple losses are more weakly dependent on plasma current. The plasma position could also be varied as a test of this mechanism, since the toroidal field ripple is highly in/out asymmetric.

The third ripple loss mechanism requires a resonance between the gyro period of an alpha and the transit time across one ripple period. At a toroidal field above $\approx 20 \mathrm{kG}$ this resonant condition can never be satisfied for $3.5 \mathrm{MeV}$ alphas in TFTR; however, this effect can potentially be studied using the faster 3 or $15 \mathrm{MeV}$ protons with the escaping alpha detectors.

\subsection{Sawteetì Effects}

The most likely anomalous transport mechanism for alphas would be a spatial redistribution of the confined alphas at sawtooth "crashes," analogous to the redistribution of plasma density and energy. Such a flattening of the fast alpha population is already incorporated into the BALDUR code used to produce Fig. 3.

Such an internal redistribution of confined alphas will not be easy to detect in TFTR. One possible method is to look for modulation in the local density of slow-confined alphas with the single or double charj-exchange diagnostics (Secs. 3.2 and 3.3), noting that the population of slow alphas responds only slowly (over $\approx \tau_{\mathrm{s}, \mathrm{e}}$ ) to modulation of the local source function (which is also modulated by the sawteeth). Another possibility is that a radial expulsion of fast-confined alphas will move these ions onto escaping alpha orbits; however, to detect these one has to first correct for the modulation of the local source rate due to the sawtooth (which could, in principle, 
be done through radially resolved neutron enission measlirements).

The basic physical mechanism by which saweeih interact with alphas deserves further study, since it is not clear that very fast ions will sullow small-scale internai magnetic perturbations [27]. The prospects for the approach to ignition will to inaproved if alphas can oe shown to be unaffected by sawteeth.

\subsection{Turbulence Effents}

The large gyroradii and banana widuns of alphas tend to redure their interaction with small-scale electrostatic or magnetic turbulence. Mynick and Krommes [28] hava shown itat the diffusion of fast alectoons in a specified turbulent field is teduced relative to the diffusion of low energy electrons yy:

$$
\mathrm{D}_{\mathrm{e}}^{\text {fast }} \approx\left(1 / \mathrm{k}_{\perp} \rho\right)\left(1 / \mathrm{k}_{\perp} \delta\right) v_{\mathrm{e}}^{\text {slow }}
$$

where $k_{\perp}$ is the typical radial wave aumber of the turbulence and $\rho$ and $\delta$ are the gyroradius anc banana width of the fast electron. The diffusion of fast alphas should be reduced similarly, which is fortunate since the fast alpha velocity is comparable to electron themal velocities and the alphas would otherwise diffuse radially at a rate comparable to eiectrons (i.e., potentially very far during an alpha slowing down time).

Measures of turbulent transport of alphas will be difficult, particularly if this transport involves loss of untrapped fast ions to the inner or outer equatorial plane (since escaping alpha detectors are difficult to operate at these hot spots). Derhaps the best diagnostic would be the burnup fraction of confined tritons measured at low density where the cross-section-weighted slowing down time might be long compared to a triton confinement time through this mechanism.

\subsection{Collective Alpha-Induced Instabilities}

Several different types of macro- or micro-instabilities can be induced through the collective effects of alphas $[22,29,30]$. Presumably these effects will appear above some threshold values of alpha density, alpha beta, or alpha pressure gradient.

Perhaps ti:e most likely of these instabilities to appear in TFTR is the alpha "fishbone"

which, according to a recent estimate by White [26], is destabilized at $\beta \alpha \approx 5 \times 10^{-3}$ (assuming that the internal kink is alsc unstable). As shown in Fig. 3, this value for alpha beta is exceeded neur the plasma center for typizal $Q \approx 1$ TFTR scenarios. This instability mighi be characterized by ejection of alphas at the outer equatoriai pline, modulation of the alpha beta, and by ICRF emission analogously to the neutral-beam-induced fishbones. 


\subsection{Alpha Heating}

Alpha heating should be first detectable through measurements of the central electron temperature, since alphas are created with peaked profiles and heat primarily electrons. Simulations of $\mathrm{Q} \approx 1$ scenarios, such as the medium density case in Table 2 , suggest that the central electron temperature will increase by as much as $30 \%$ with the switch from $D / D$ to $D / T$. However, systemaric effects associated with this switch (such as possible changes in confinement with ion mass) might make such measured temperature changes ambiguous.

Perhaps the first hints of alpha heatiıg will come from transient effects, such as the delayed decay of the central electron temperature after beam turnoff due to the relatively long slowing down time of alpias compared to neutral beam ions, or from an increased rate of rise of central temperature between sawtooth crashes. The magnitude of such effects will depend in part on the confinement properties of alpha- $\}_{1}$ eated plasmas, which is the principal physics issue to be addressed by the next generation of ignited plasmas.

\section{Conclusions}

- TFTR will be used to study whether alphas and alphalike füion products behave according to the predictions of the classical confinement and thermalization niodels Several new diagnostics will be developed for these studies, including radiation-resistant escaping alpha detectors and slowconfined alpha detectors.

Specific physics issues to be addressed include the effects of plasma current, toroidal field ripple, sawteeth, and urbulence on alpha confinement. At its $Q \approx 1$ performance level TFTR can also be used to begin the study of the collective behavior of alpha particles and the effects of alpha heating cn plasma confinement.

\section{ACKNOWLEDGMENTS}

I ?ank E. Cecil, G. Hammett, W.W. Heidbrink, D. Mikkelsen, H. Mynick, R. White, K.M. Young and particularly J. D. Strachan for their contributions to this paper. This work was supported by U.S. DOE Contract No. DE-AC02-76-CHO-3073. 
Fusion Reactions;

$$
\begin{aligned}
D+T & =n(14 \mathrm{MeV})+\alpha(3.5 \mathrm{MeV}) \\
D+D & =n(2.5 \mathrm{MeV})+{ }^{3} \mathrm{He}(0.8 \mathrm{MeV}) \\
& =\mathrm{T}(1 \mathrm{MeV})+\mathrm{p}(3 \mathrm{MeV}) \\
D+{ }^{3} \mathrm{He} & =p(15 \mathrm{MeV})+\alpha(3.7 \mathrm{MeV})
\end{aligned}
$$

\begin{tabular}{|c|c|c|c|}
\hline FUSION PRODUCT & $\begin{array}{l}\text { MAXTMUM } \\
\text { PRODUCTION } \\
\text { RATE }\left(\mathrm{s}^{-1}\right)^{\mathrm{a}}\end{array}$ & $\begin{array}{l}\text { TYPICAL } \\
\text { TOROIDAL } \\
\text { GYRORADIUS } \\
(\mathrm{cm})\end{array}$ & $\begin{array}{l}\text { TYPICAL } \\
\text { SLOWING DOWN } \\
\text { TIME } \\
\text { (s) }^{\mathrm{C}}\end{array}$ \\
\hline $3.5 \mathrm{MeV} \alpha$ & $>10^{19}$ & 5.4 & 0.35 \\
\hline 3.7 $\mathrm{MeV} \propto$ & $10^{15}-10^{16}$ & 5.7 & 0.35 \\
\hline $1.0 \mathrm{MeV} \mathrm{T}$ & $\Sigma_{10^{16}}$ & 5.0 & 1.1 \\
\hline $3.0 \mathrm{MeV} \mathrm{p}$ & $\tilde{>}_{10^{16}}$ & 5.0 & 0.35 \\
\hline $0.8 \mathrm{MeV} 3 \mathrm{He}$ & $\widetilde{>}_{10^{16}}$ & 2.3 & 0.26 \\
\hline $15 \mathrm{MeV} \mathrm{p}$ & $10^{15}-10^{16}$ & 11.2 & 0.35 \\
\hline
\end{tabular}
a Beam-target reaction rate at $E_{b} \equiv 100 \mathrm{keV}$ and $P_{b} \equiv 25 \mathrm{MW}$
${ }^{b}$ Evaluated assuming $90^{\circ}$ pitch angle at $50 \mathrm{kG}$
$c_{\text {Assuming }} \mathrm{T}_{e}=10 \mathrm{keV}$ and $\mathrm{n}=10^{14} \mathrm{~cm}^{-3}$. 
TABLE II.

TFTR $Q \approx 1$ SCENARIOS

\begin{tabular}{|c|c|c|c|}
\hline & Low $\mathbf{n}$ & Medium n & High $n$ \\
\hline RUN NO. & TQR111 & TJQ009 & TJO052 \\
\hline $\mathrm{I}_{\mathrm{p}}(\mathrm{MA})$ & 2.5 & 2.5 & 3.0 \\
\hline$\dot{\mathrm{B}}_{\mathrm{T}}(\mathrm{T})$ & 5.2 & 5.2 & 5.2 \\
\hline $\mathrm{n}\left(10^{14} \mathrm{~cm}^{-3}\right)$ & 0.51 & 0.74 & 1.1 \\
\hline$P_{\text {beam }}(\mathrm{MW})$ & 27 & 28 & 28 \\
\hline $\mathrm{P}_{\mathrm{RF}}(\mathrm{MW})$ & -- & $\cdots$ & 7 \\
\hline Heating(s) & 2 & 2 & 2 \\
\hline$Z_{\text {eff }}$ & $\sim 1.5$ & $\sim 1.5$ & $\sim 1.2$ \\
\hline $\mathrm{n}(0) 10^{14} \mathrm{~cm}^{-3}$ & 0.65 & 1.1 & 2.1 \\
\hline $\mathrm{T}_{\mathrm{j}}(0)(\mathrm{keV})$ & 41 & 20 & 12.8 \\
\hline $\mathrm{T}_{\mathrm{e}}(0)$ & 13 & 9.2 & 7.4 \\
\hline$<\beta>(\%)$ & 2.2 & 1.6 & 1.4 \\
\hline$\tau_{E^{(a)}(s)}$ & 0.36 & 0.27 & 0.18 \\
\hline$B(0)_{\text {tor }}(\%)$ & 4.5 & 4.4 & 6.0 \\
\hline$<\beta_{\alpha}>(\%)$ & 0.26 & 0.11 & 0.04 \\
\hline$P_{\alpha}(M W)$ & 4.4 & 4.8 & 3.8 \\
\hline $\mathrm{P}_{\alpha . \mathrm{Iost}}(\mathrm{MW})$ & 0.5 & 0.4 & 0.1 \\
\hline$\tau_{E^{(\mathrm{a} / 2)(s)}}$ & 0.38 & 0.34 & 0.23 \\
\hline $\mathrm{n}(0) \mathrm{T}_{\mathrm{i}}(0) \tau_{\mathrm{e}}(\mathrm{a} / 2)\left(10^{18} \mathrm{~cm}^{-3} \mathrm{eVs}\right)$ & 0.6 & 0.99 & 0.7 \\
\hline$Q_{\text {inst }}$ & 1.0 & 1.0 & 0.55 \\
\hline (\%) beam-target & 40 & 35 & 18 \\
\hline
\end{tabular}




\section{REFERENCES}

[1] Murphy, T.J. and Strachan, J.D., Nucl. Fusion 25, 383 (1985).

[2] Hively, L.M. and Miley, G.M., Nucl. Fusion 17, 1021 (1977); also, Hively, L.M., Ph. D. thesis, Univ. of Illinois, 1980.

[3] Mikkelsen, D., Physics of Plasmas in Thermonuclear Regimes, (Edited by B. Coppi and W. Sadowski), DOE Cong. 790866 (1979).

[4] Gerdin, G., et al, Fusion Technol, 7, 181 (1985).

[5] Post, D.E., Applied Atomic Collision Theory, Academic Press (1984).

[6] Mikkelsen, D. , Princeton University, private communication (1986).

[7] Post, D.E., et al, J. Fuion Energy 1, 129 (1981).

[8] Zweben, S.J., Redi, M.H., and Bateman, G., Princeton Plasma Physics Laboratory Report PPPL-2316 (1986).

[9] Zweben, S.J., Rev. Sci. Instrum. 57, 1723 (1986).

[10] Heidbrink, W.W., Chrien, R.E., and Strachan, J.D., Nucl. Fusion 23, 917 (1983).

[11] Strachan, J.D., et al., Proc. Workshop on Basic Processes in Toroidal Fusion Devices, Varenna (1985) Accepted for publication.

[12] Zweben, S.J., Rev. Sci. Instrum. 57, 1774 (1986).

[13] Fonck, R.J., Rev. Sci. Insrum. 56, 885 (1985).

[14] Post, D.E., Grisham, L.R., and Medley, S.S., Nuc. Technol./Fusion 3, 457 (1983).

[15] Hammett, G., Ph.D. thesis, Princeton Univ. 1986.

[16] Nieschmidi, E., Princeton University, private cornmunication (1986).

[17] Cecil, E., Princeton University, private communication (1986).

[18] Strachan, J.D., Rev. Sci. Instrum. 57, 1771 (1986).

[19] Cecil, E., Zweben, S., and Medley, S.S., Nucl. Instrum./ Methods A245, 547 (1986).

[20] Moses, K., private communication (1986).

[21] Cottrell, G.A., et al, Proc. $13^{\text {th }}$ Eur. Conf. on Conc. Fus. and Plasma Heating, Schlieresee (1986) Accepted for publication.

[22] Kolesnichenko, Y., Nucl. Fusion 20, 727 (1980)

[23] Bitconi, E. and Haegi M., 12th Eur. Conf. on Plasma Physics, Budapest, (1985) Vol. I, p. 211.

[24] Goldston, R.J., White, R.B., and Boozer, A.H., Phys. Rev. Lett. 47, 647 (1981).

[25] Putvinskii, S.V. and Shurygin V.V., Sov, J. Plasma Phys. Sept-Oct. (1984) 534.

[26] White, R.B. , Princeton University, private communication (1986).

[27] Zweben, S.J., es al, Nucl. Fusion 23, 477 (1980).

[28] Mynick, H.E. and Krommes, J.A., Phys. Fluids 23, 1229 (1980).

[29] Lisak, M., Anderson, D., and Hamnen, H., Phys. Fluids 26, 3308, (1983).

[30] Sigmar, D.J., MIT Report PFC/CP-86-9 (1986). 


\section{FIGURE CAPTIONS}

1. Typical alphe particle orbits in TFTR. Each particle starts out at the outer equatorial plane at a radius of $r / a=0.25$ in a plasma with a parabolic-cubed furrent profile. In (a) the plasma current is $1.5 \mathrm{MA}$ and the initial pitch angle is $30^{\circ}$, in (b) the plasma current is also $1.5 \mathrm{MA}$ but the initial pitch angle is $-30^{\circ}$, and in (c) the plasma current is $3.0 \mathrm{MA}$ and the initial pitch angle is the same as for (b).

2. Confined alpha fraction vs. plasma current in TFTR. The upper curve is obtained assuming plasma current profile of parabolic-to-the-jourth and an alpha source profile of parabolic-to-the-sixth (peaked profiles), while the lower curve is obtained assuming first and second order parabolic profiles, respectively (flat profiles).

3. Computer code simulations of alpha-particle-related quantities for typical $Q \approx i$ scenarics in TFIR.

4. Design for a pitch angle and energy-resolved escaping alpha detector for TFTR.

5. Predicted flux into the escaping alpha detector of Fig. 4 vs pitch angle for two plasma currents in TFTR. The relarive alpha flux is calculated assuming an aperture pair $1 \mathrm{~mm}^{2} \times 1 \mathrm{~mm}^{2}$ separated by $3 \mathrm{~mm}$, normailized to the total neutron (i.e., alpha) creation rate. The pitch angle is labelled 0 for alphas perpendicular to the toroidal fieid at the detector. 

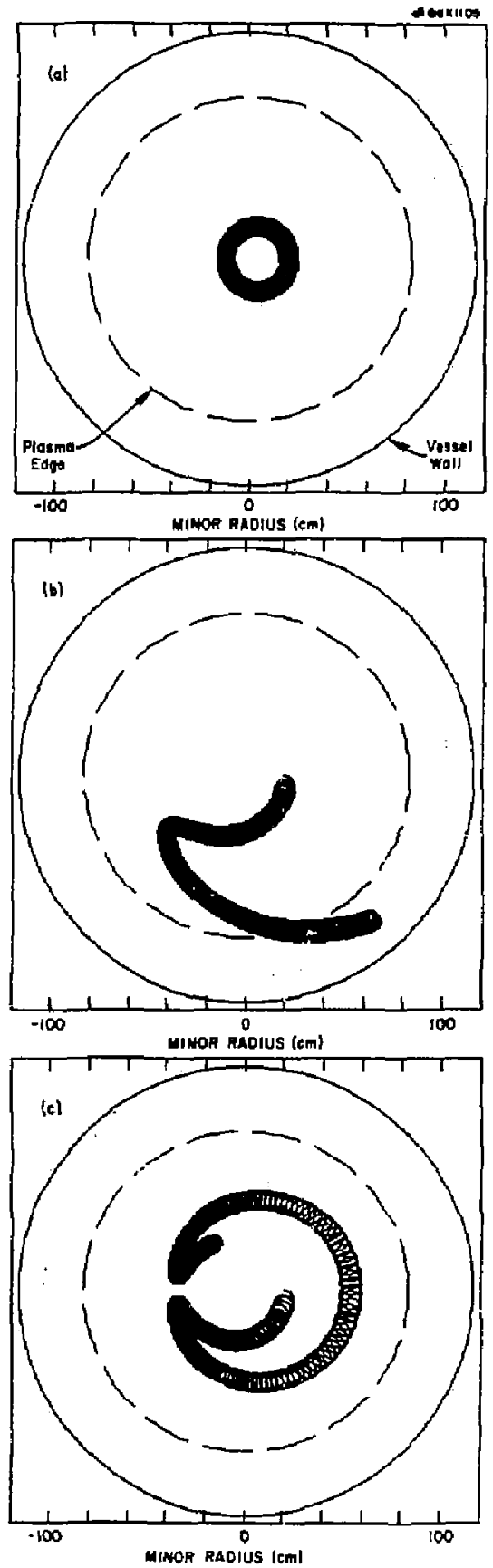

Eig. 1 




Fiq. 2 

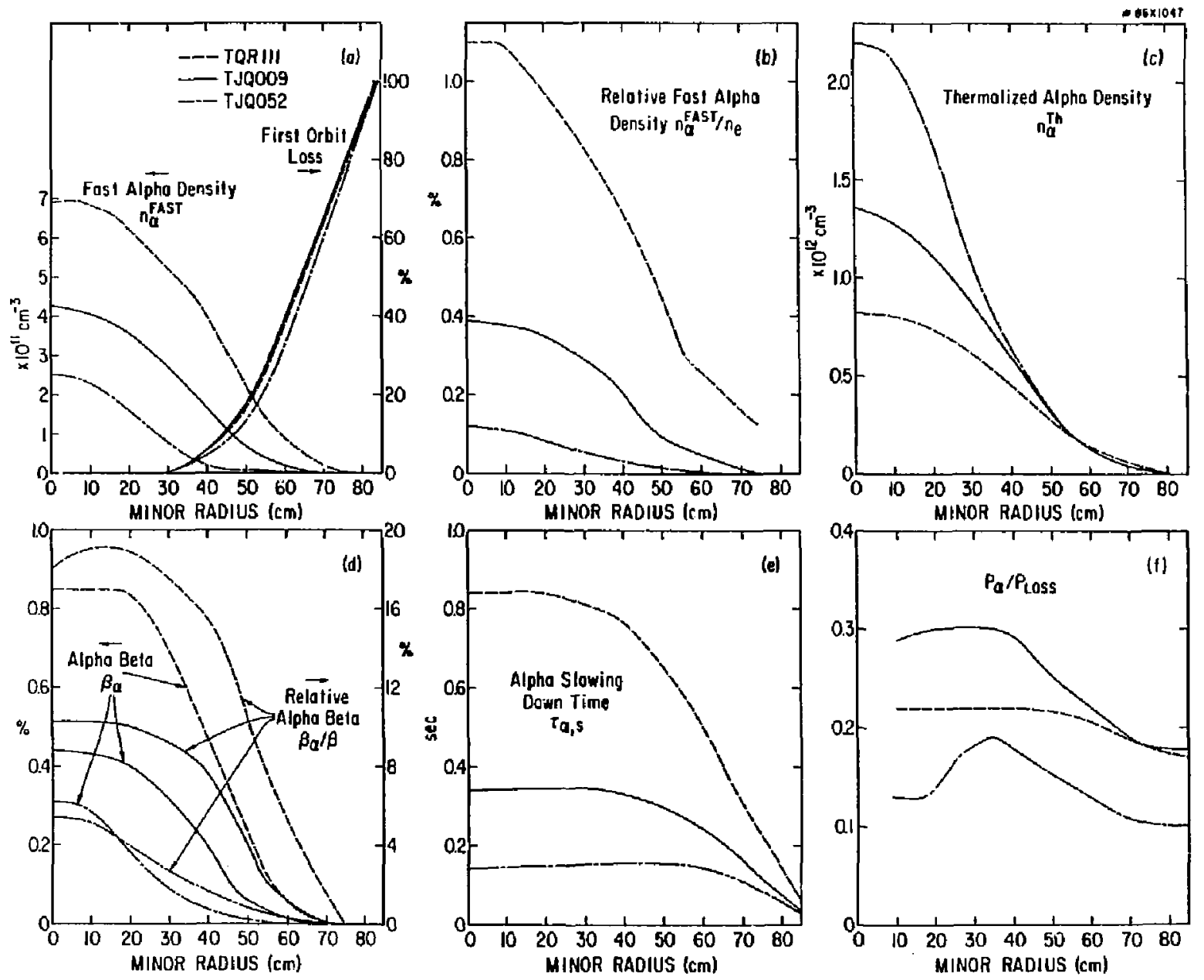

litg. 3 


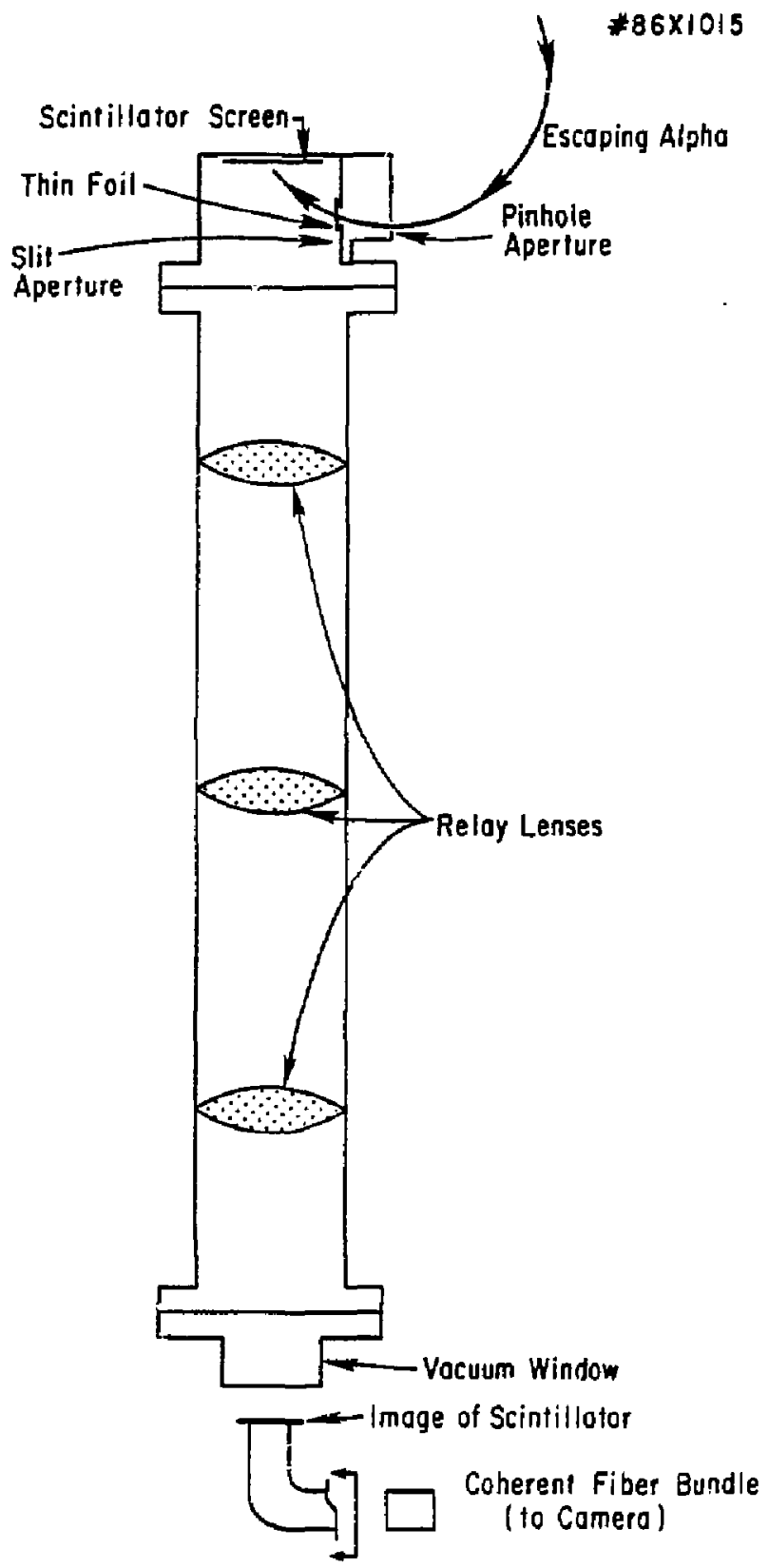

Fig. 4 


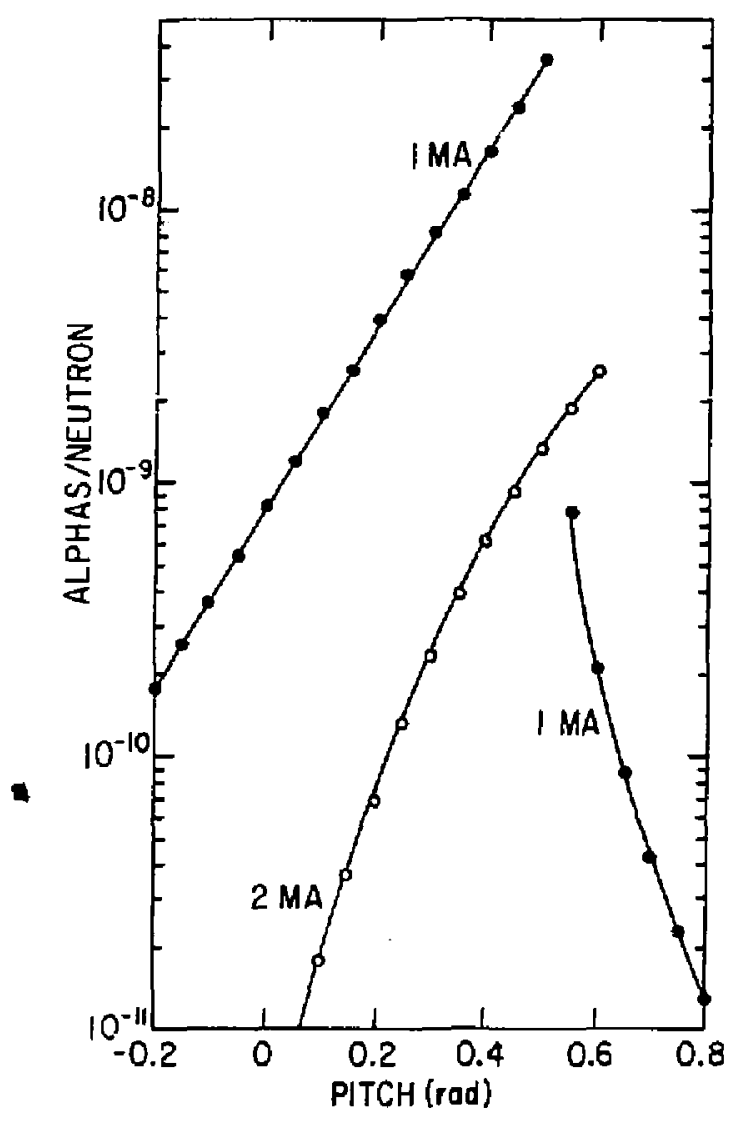

Eig. 5 
Dr. Frank J. Pesiont, Univ of wollongong, AUSTRALIA Prof. MnH. Brennan. Univ Sydney, AusTralia Plasma Rosagreh Lab.. Australtan Nat, Unly, NuSTRAliA Prot. I.R. Jones, FIInders UnIV., AUSTRALIA Prof. F. Cap, ingt Theo Phys, AUSTRla Prof. H. Heindler, Institut fur TheoretIsche Physlk, Austrin M. Goossens, Astrinomisch Instituut, BELGIUM Ecole Royale Militalro, Lab de Phys Plasmas, BELGIUM Con, of European, Og XII Fuston Prog, BELGium Prof. R. Bouclais, Laboratorlua voor Notuurhunde, BELGIUA Or; P.H. Sakanako, Univ Estadual, BRAZIL

Iństituto De Pesqulsas Espaclasi-IMPE, ERAZIL ¿LIbrary, Atomic Energr of Caneda LImited, CNNADA Or. M.P. Bachynskl, MPB Technologies, InC., CANADA Dr. H.H. Skersgard, Uaty of Saskatchewan, CANADA Dr. H. Barriard, University of Brltish Coilinbla, CNAPDA Prot. J. Telchnana, Univ, of Montreal, CANADA Prof. S.R. Sreenivasan, UnIversity of Calgary, CANADA Prof. Tudor H. Johnston, INRS-Energle, CANADA Ur. C.R. Janes, UnIY. of Alberta, CNADA Dr. Peter Lukac, Komenskeho UnIV, CZEChOSLOVAKIA The LIDrarlan, CuInen Laboratory. EHGLAND Mrs. S.A. Hutehlison, JET LIbrary, ENGLND C. Mosttet, Lab. de Physlque des Hilleux Ionlsés, FRAKCE J. Radet, CEN/CNDARACHE - Bat 506, FRANCE Dr. Tom Mual, Acadamy BIbllographic, hONG KONG Proprint Library, Cont Res Inst Phys, huNGARY Dr. B. Dasgupta, Saha list, INDiA Dr. Rok. Chhojlant, Yikran Univ. INDiA Dr. P. Kaw, Institute for Plasa Research, INIA Or. Phillip Rosenau, Israel inst Tech, ISAAEL Prof. 5. Cuperaan, Tel Aviv Unlverslty, ISRAEL Librarlan, Int'I Ctr Thes Phys, ITALr Prof. G. Rostagni, Univ ol Padova, ITAY Miss CIalla da Palo, Assoc EuRATOH-ENEA, ITALY Biblloteca, dol CNR EURATOM. ITALY Dr. H. Yanato, Toshiba Res a BeY, JAPA Prof. 1. Karakal, Atoalc Energy Res. Instltuto, JAPAN Prot. KyojT Nishlkawa, Univ of Htroshima, JAPAN Direc. Dept. Lg. Tokamak Res. JAERI, JAPAk Prot. Satoshi Itoh, Kyushu Unlvarsity, JAPNA Raseareh into Centor, Hagoya Univarsity. JNAN Prot. S. Tanaka, Kyoto Unl yorslty, JNAN Library, Kioto UnIverslty, JAPAN Prof. Mobuyuki Inoue, Unlversity of Tokyo, JAPAH S. MOri, JAERI, JAPAN H.H. KIm, Korea Advancad Energy Resuarch Instltute, KOREA Prof. 0.1. Chol, Adv, Inst Sel \& Tech, KOREA Prof. B.5. I. I I U, University of Walkato, NEW ZEALAND Institute of Plasma Physles, PEOPLE'S REPUBLIC OF CHINA Librarlan, Instifuta of Phys., PEOPLE'S REPUALIC OF CHINA Library, TsIng Hut UnIversity, PEOPLE'S REPUALIC OF CHINA
2. Ll, Southwest Inst, Physics, People's RePUblic OF CHINA Prot. J+A.C. Cabral, Inst Superlor Tecn, PORTUGAL Dr. Octavian Petrus, AL I CU2A University, ROMANIA Or. Johse de Villlars, Plasma Physles, AEC, SO AFRICA Frof. M.A. Hallberg, University of Natal, SO AfRICA Fusion OTY. Library, JEN, SPAIX Or. Lennart 5tr, iflo, University Of UMEA, SWEOEN LIbrary, Royal Inst Tech, SWEDEN Prot. Hans wi thelrson, Chalmars Univ Tech, ShEOEN Centro Phys des Plasmes, Ecole Polytach Fad, SWITZERLAND Bibllathoek, Fon-l nst Yoor Plasman-Fysica, THE NETHERLANDS Dr. D.D. Ryutor, SIberian Acad SCl, USSR Dr. G.A. Ell seov, Kurchatoy Instituta, US5R Dr. $V, A_{*}$ Gluknikh, Inst Electro-Physical, USSR Dr. V.T. Tolok, Inst. Phys. Toch. USSR Dr. L.M, Kovrlzhnykh, Instltute Gen. Physics, JJsSR Prof. T.J.M. Boyd, Unir College N Males, WALES Nuclear Res, Estobilshment, dullich Ltd., W. GERMWY Bibllothak, Inst. Fur Plasmaforschung, H. GERMANY Dr. K. Sehindler, Ruhr Unlvorsitat, W. GERMANY ASOEX Rooding Fon, IPP/Max-Planek-1 nstItut fur Plosinophysik, W. GERMANY LIbrarlan, Moxplanck Institut, W. GERMANY Prof, R.K. Joner, Inst Phys, Yugoslayia 